\title{
O sujeito cerebral: um esboço histórico e conceitual
}

(original em Francês, Le Sujet Cérébral, publicado na PSN, volume III, numéro 11, janvier-

février 2005)

El sujeto cerebral: un esbozo histórico y conceptual

The cerebral subject - an historical outline on the anthropology

of "brainhood"

\section{Fernando Vidal}

Instituto Max Planck de História das Ciências, Berlim, Alemanha.

\section{Resumo}

Desde meados do século XX, numerosos discursos e práticas, dentro e fora das disciplinas científicas e filosóficas, têm apresentado o desenvolvimento da noção de ser humano como um 'sujeito cerebral'. O cérebro é concebido como a única parte do corpo que devemos possuir, e que deve ser nossa, para que sejamos nós mesmos. Já que a personalidade é a qualidade ou condição para ser considerado um indivíduo, a 'cerebralidade' é, dessa forma, a qualidade ou condição de ser um cérebro. Esta propriedade define o sujeito cerebral. A antropologia da 'cerebralidade' pode parecer uma conseqüência natural do progresso das neurociências - mas procede de desenvolvimentos das filosofias da matéria e da identidade pessoal do século XVII. As neurociências confirmam e reforçam esta perspectiva. O autor delineia a narrativa histórica relacionada ao desenvolvimento do sujeito cerebral assim como alguns temas contemporâneos que surgem a partir das neurociências.

Palavras-chave: Cerebralidade, Corpo, Identidade Pessoal, Sujeito Cerebral

\section{Resumen}

Desde los medios del siglo XX, numerosos discursos y prácticas, adentro y afuera de las disciplinas científicas y filosóficas, han demostrado lo desarrollo de la noción de ser humano como un 'sujeto cerebral'. El cerebro es concebido como la única parte del cuerpo que debemos poseer y que debe ser nuestra para que seamos nosotros mismos. Como la personalidad es la cualidad o condición para ser considerado un indivíduo, la 'cerebralidad' es así la cualidad o condición de ser un cerebro. Esta propiedad define el sujeto cerebral. La 
antropología de la 'cerebralidad' puede parecer una consecuencia natural del progreso de las neurociencias - pero procede de los desarrollos de las filosofias de la materia y de la identidad personal del siglo XVII. Las neurociencias conferman y fortalecen esta perspectiva. El autor delinea la narrativa histórica relativa a lo desarrollo de lo sujeto cerebral así como unos temas de las neurociencias.

Palabras clave: Cerebralidad, Cuerpo, Identidad Personal, Sujeto Cerebral

\begin{abstract}
Since the middle of the 20th century, numerous discourses and practices, both within and outside scientific and philosophical disciplines, have manifested the development of the notion of the human being as a cerebral subject. The brain appears to be the only organ of the body that we need, and that has to be exclusively ours, in order for each individual to be himself or herself. Since personhood is the quality or condition of being an individual person, brainhood is thus the quality or condition of being a brain. This property defines the cerebral subject. The anthropology of brainhood may seem a natural consequence of progress in the neurosciences. However, it is rooted in 17th-century developments in the philosophies of matter and personal identity. The neurosciences confirm and reinforce this perspective. The author outlines the historical narrative concerning the development of the cerebral subject as well as some contemporary issues arising from the neurosciences.
\end{abstract}

Keywords: Brainhood, Body, Personal identity, Cerebral subject

"Ele pensa, logo ele vende". lhe outorga a lei sobre a propriedade Jonathan Keats, um artista de São intelectual Francisco, registrou os direitos de seu (http://cnewmark.com/keats.html; Singel. cérebro como se esse fosse uma escultura 2003). Menos lúdicos, alguns de seus fabricada pelo pensamento, depois colocou compatriotas seguem a última moda em seus neurônios à venda no mercado, matéria de criogenia: congela-se o cérebro lançando seu negócio com uma apresentação pública de imagens digitais de seu cérebro em atividade. Keats espera reunir fundos suficientes para cobrir o custo de manter o órgão em funcionamento pelo menos 70 anos após sua morte, o que unicamente, que permanece desse modo a espera do dia em que ele poderá ser posto em funcionamento para sempre. É a chamada 'neuropreservação' (http://www.alcor.org/FAQs/faq02.html\#n europreservation). A idéia não é totalmente 
nova. Em um conto de 1960, Roald Dahl relata como William, agonizando, escolhe sobreviver sob a forma de um cérebro flutuante em uma solução, com um globo ocular afixado para continuar a ler o jornal (Dahl, 1979). Encontra dificuldade de fazêlo, visto que sua mulher faz a partir de então diante "dele" todas as coisas que o desagradam... No que concerne o modo de sobrevida de seu herói, Dahl utiliza tão somente um motivo já corrente na ficção. Ora, mesmo que, uma vez que estão vivos, nem os personagens reais, nem os fictícios se apercebem como estando literalmente reduzidos ao cérebro, é conservando-o que eles esperam sobreviver.

O cérebro é reconhecido como sendo a única parte do corpo que devemos possuir, e que deve ser nossa, para que sejamos nós mesmos; ele aparece como o único órgão indispensável a existência do eu e a manutenção da identidade pessoal. Ocorre com ele algo diverso do que com o resto do corpo. Se transplantarmos o cérebro de $\mathrm{A}$ para o corpo de $\mathrm{B}$, não é $\mathrm{B}$ que recebe um novo cérebro, mas $\mathrm{A}$ que ganha um novo corpo. É na medida em que o cérebro define a pessoa, que somos um sujeito cerebral. Existe aqui muito mais do que um jogo de artista conceitual ou de uma fantasia de loucos por eternidade.

O que acabamos de nomear sujeito cerebral impõe-se como uma figura antropológica, cuja importância não cessa de aumentar desde meados do século XX, e cujas manifestações se multiplicam fora das disciplinas mais diretamente afins. Estaríamos tentados a atribuir suas origens ao progresso das neurociências. Gostaríamos, entretanto, de sugerir um percurso inverso. A idéia de que somos essencialmente nosso cérebro precede o desenvolvimento das neurociências para enraizar-se nas filosofias da matéria e da identidade pessoal do fim do século XVII. Desde o século XIX, dados científicos parecem corroborá-la. Nos anos 60, as ficções relativas ao cérebro tornam-se um instrumento aparentemente incontornável para filosofar sobre a identidade pessoal. É mais ou menos desta época que podemos datar o predomínio da 'cerebralidade' como propriedade definidora do ser humano, bem como do sujeito cerebral como figura antropológica. A utilização das ficções filosóficas sobre o cérebro coincide cronologicamente com o crescimento do peso simbólico, institucional e financeiro da pesquisa neurocientífica, e com a percepção de que se trata de um dos domínios mais decisivos para o futuro da humanidade. Esta convicção afirma-se cada vez mais. Os anos 90 foram o Decênio do Cérebro; acreditando-se em Jean Pierre Changeux, o século XXI será o século (Changeux, 
2000). Diversas tentativas emergem para captar os fundamentos cerebrais de fenômenos individuais ou sociais, como para aproximar as ciências humanas das neurociências ou pensar os numerosos problemas levantados por essas últimas.

Com efeito, as disciplinas 'neuro' se multiplicam. O prefixo existe desde o século XVI tal qual, mas o termo 'neurociências' nasce nos anos 60 . Palavras análogas seguiram-se, e falamos hoje não somente de neuropediatria, de neuropsiquiatria, ou de neurogerontologia, de neurolingüística, ou de neuropsicologia, mas também, pouco a pouco, de neurofilosofia, neuroeducação, neuroestética, neuroética, neuroeconomia, neuroteologia, neuropsicanálise... Mesmo que estas áreas tornem-se autônomas ou permaneçam como zonas de intersecção ou de interação entre as neurociências e as ciências humanas, seus nomes são por si próprios significativos. Eles desvelam o poder publicitário e legitimador das atividades que chamam para si as ciências do cérebro. Ao mesmo tempo, a nomenclatura em voga declara a novidade dos desafios que lançam as neurociências e a esperança que elas levantam de chegar a compreender os fundamentos neuronais dos processos estudados pelas ciências humanas, até mesmo de remanejar essas se apoiando no conhecimento do cérebro. A neuroética distingue-se pelo fato de não se limitar a pesquisa das bases neurológicas do comportamento moral; antes, ela acentua as conseqüências éticas, sociais, legais e mesmo políticas dos saberes neurocientíficos (Blank, 1999, Marcus, 2004).

Nenhum desses domínios é homogêneo e, apesar de suas tendências reducionistas e córtico-cêntricas, bem como sua confiança algumas vezes acrítica frente às técnicas de imagem cerebral, eles tendem a pesquisar na interdisciplinaridade e no diálogo entre as disciplinas. Diferentemente interessadas estão as empresas com o objetivo lucrativo, como a neurotecnologia, o neurofitness ou a neuropreservação já mencionada. Ora, todos são sinais não somente da presença das neurociências na cultura contemporânea, mas também de uma progressão notável na cerebralização do sujeito. É o desenvolvimento desse sujeito cerebral que eu gostaria aqui de discutir em uma perspectiva histórica.

\section{A alma e o cérebro}

Primeiramente, convém diferenciar a questão do sujeito cerebral daquela das relações entre alma e o corpo. Para simplificar podemos dizer que, na história das idéias concernente a essas relações, 
houve no mundo cristão ocidental dois momentos teóricos principais (aristotélico e pós-aristotélico) e uma tradição fisiológica derivada de Galeno.

\section{A alma como forma e a alma racional}

De acordo com um esquema que prevalece até o fim do século XVI, a alma (psukhè, anima) está definida nos termos de Aristóteles, como a "forma" de um corpo natural que tenha vida em potência (Aristóteles, 1966; 412a20). Ela é um princípio de vida que permite a realização das potencialidades de certos tipos de matéria e não pode realmente ser separada do corpo. Se o olho fosse um animal completo, diz Aristóteles, "a vista seria a alma dele"; ora, o olho "é a matéria da visão e essa desaparecendo, ele não é mais um olho, se não por homonímia como um olho de pedra ou desenhado" (Aristóteles, 1966, 412b20). Assim concebida, a alma é responsável por todas as funções essenciais dos seres vivos. Essas são tradicionalmente definidas como faculdades: vegetativas (nutrição, crescimento e reprodução), sensitivas e motoras (sentidos externos e internos, movimento físico e faculdade apetitiva), e racionais ou intelectivas (Wright, Potter, 2000). O ser humano possui todas essas faculdades; os animais não humanos possuem apenas as sensitivas, motoras e vegetativas; as plantas somente as últimas. Mas todos são "animais" com corpos providos de uma alma; eis porque até o fim do século XVII, o termo 'psicologia' (já utilizado em torno de 1570) designa uma ciência genérica dos seres vivos (Vidal, 2006).

A alma intelectual ou racional levanta problemas particulares. Aristóteles fala de uma "inteligência ativa" separável, imortal e eterna. Esta noção de aparência pouco Aristotélica engendra intermináveis debates. Entretanto, no século XIII, a igreja declara que alma é uma substância indivisível e que a alma racional é per se et essentialier a "forma" do corpo. Mais tarde, com a desintegração dos quadros aristotélicos, a alma cessa de ser responsável pelas funções vegetativas, nutritivas e sensitivas e, como na filosofia de René Descartes (1596-1650), ela tornase igual ao espírito (mens) ou alma racional. Essa transformação do conceito de alma torna problemática as relações entre alma e corpo.

Nos séculos XVII e XVIII, enumeramos três posições principais (Baertschi, 1992). De acordo com o sistema da 'influência física', as duas substâncias agem materialmente uma sobre a outra. No 'ocasionalismo' do padre Nicolas Malebranche (1638-1715), Deus é o agente causal de seu laço: quando a alma 
quer fazer mexer o corpo, Deus o faz se mexer. Finalmente, Gottfried Wilhelm Leibniz (1646-1716) compara a relação da alma e do corpo àquela de dois pêndulos perfeitamente sincronizados, regulados por uma 'harmonia preestabelecida'. Tende-se então a diferenciar o postulado da união alma-corpo da questão das modalidades empíricas de seu "comércio". Enquanto que a união é aceita como um fato, misterioso em si próprio, mas confirmado pela fé, a razão e experiência, a interação ou commercium tornam-se um objeto próprio da psicologia empírica tal qual ela se desenvolve no século XVIII (Vidal, 2006).

\section{A tradição fisiológica de Galeno}

A despeito das diferenças fundamentais entre os momentos aristotélicos e pós-aristotélicos, a maneira de conceber a interação da alma e do corpo repousou durante numerosos séculos sobre as teorias fisiológicas de Galeno, filósofo e médico grego do século II (Temkin, 1973). Apoiando-se em idéias atribuídas a Hipócrates, médico grego nascido aproximadamente em 460 a.C., Galeno define a saúde como o equilíbrio entre os quatro fluidos ou "humores" do corpo: o sangue, a bile amarela, a bile negra e a fleuma. Esses humores são compostos por quatro elementos e suas qualidades (o fogo/quente, o ar/frio, a água/úmida e a terra/seca). Suas combinações e dosagens no corpo constituem "temperamentos"; esses determinam a personalidade e as capacidades do indivíduo, como declara o título do influente tratado galênico, Quod animi mores corporis temperamenta sequantur (As faculdades da alma acompanham os temperamentos do corpo) (Galeno, 1995). O ser humano é um composto de duas substâncias, o corpo e a alma ligados intimamente entre si e em constante interação.

Resta explicar esta interação. O corpo segundo Galeno comporta três sistemas: o cérebro e os nervos, o coração e as artérias, o fígado e as veias. O sangue formado no fígado é transportado pelas veias para o resto do corpo, onde ele serve a nutrição e ao crescimento sob a forma de um 'espírito natural'. Após misturar-se ao ar nos pulmões e passado no coração ele se transforma em dois tipos de pneuma: uma parte torna-se 'o espírito vital' de que dependem as funções vitais e locomotoras; outra dá ao cérebro 'o espírito animal' necessário as sensações e as funções intelectivas. As qualidades (temperatura, densidade, etc.) desses espíritos procedem dos humores, em particular do sangue: se esse é muito frio, os espíritos animais correm o risco de assim o serem e os atos 
mentais que deles dependem serão então fracos e lentos.

$$
\text { Localizadas nos ventrículos }
$$
cerebrais entre os quais circulam os espíritos animais, as faculdades articulamse entre si a partir do princípio de que nada há no intelecto que não tenha passado primeiro pelos sentidos. Os dados dos sentidos externos (visão, audição, paladar, tato e olfato) estão reunidos por um dos sentidos internos, o "senso comum" (sensus communis), colocando em funcionamento a memória, bem como a imaginação sob suas formas passiva e ativa (via imaginativa, fantasia) (Figura 1). Sobre a base das imagens sensíveis assim geradas, o intelecto forma os conceitos e realiza suas outras operações específicas (Clarke, Dewhurs, 1972; Harvey, 1975;
Kemp, 1990). O cérebro preenche a função essencial de fabricar e de guardar os espíritos animais, mas são esses espíritos por si mesmos, e o temperamento no seu conjunto, que ditam o caráter e as aptidões de uma pessoa. Exemplar desta tradição é o célebre 'Exame de engenhos pelas ciências'. Seguindo o Quod animi mores, o médico espanhol Juan Huarte de San Juan (1530?-1592) estabelece aí as correspondências entre o úmido e a memória, o seco e o entendimento, o quente e a imaginação, e delas tira conselhos e prescrições concernentes as atitudes e as inclinações individuais, bem como os ofícios (dos mais humildes aos mais elevados) aos quais convém a cada um se consagrar em função de seu temperamento (Huarte, 1989).

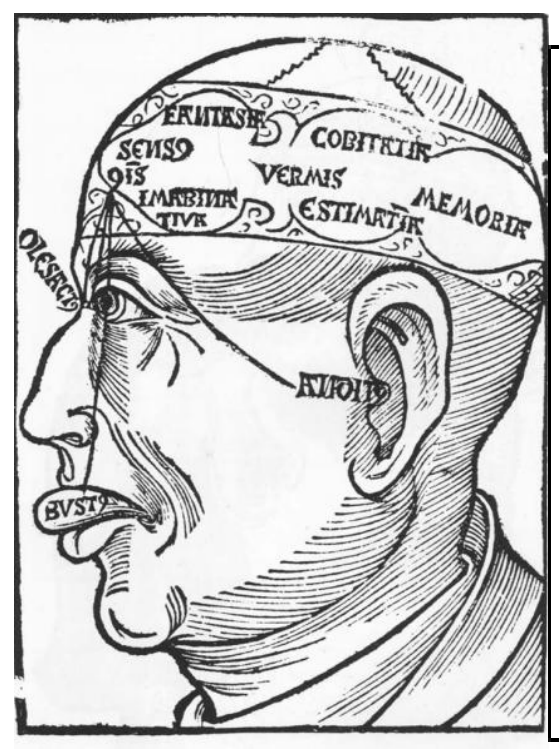

Figura 1. Nessa tardia versão de uma representação freqüunte, a partir da Idade Média, a língua, o ouvido e o nariz (gustus, audictus, offactus), estão ligados ao senso comum, situado no ventrículo anterior junto à fantasia e à imaginação. Entre os ventrículos anterior e médio situatm-se os lóbulos do vérmix, apresertados como responsáveis pelo fluxo dos instintos animais.

In Hieronymus Brunschwig, The noble experyence of the virtuous handy warke of surgery, Londres, 1525 (1 a ed. aleman, 1497) 


\section{$O$ órgão da alma}

Nos séculos XVII e XVIII, o momento em que a teoria humoral perde sua importância, os nervos, concebidos como fibras sólidas e elásticas ou como tubos ocos tornam-se os intermediários entre a alma e o corpo. Seu hipotético ponto de convergência no interior do cérebro é freqüentemente considerado como "sede da alma", quer dizer, não um lugar em que a alma se encontraria materialmente, mas o órgão onde ela interage com o corpo. Para Descartes, a alma exerce "imediatamente" suas funções junto à glândula pineal. Pelo fato dela não ser dupla, a epífise é escolhida como o órgão onde as impressões transmitidas pelos órgãos sensoriais (sempre duplos) reúnem-se em uma única percepção. De acordo com a tese cartesiana, os espíritos animais circundam a glândula pineal. Quando a alma quer recordar-se de alguma coisa, sua vontade faz com que a glândula mova os espíritos até que eles encontrem os traços do objeto em questão (as recordações, explica Descartes, formam-se pelo alargamento dos poros da glândula sob o efeito da passagem dos espíritos animais) (Descartes, 1649, 1664). Thomas Willis (1621-1675) contrariamente
Descartes, anatomista e médico inglês, postula a localização distribuída das faculdades da alma. A imaginação sendo uma ondulação dos espíritos do centro do cérebro para sua circunferência, tem sua sede no corpo caloso. A memória depende dos espíritos impulsionados da periferia para o centro; sua sede é então no córtex. A coordenação sensorial é feita no corpo estriado. Colocado entre a mencionada medula oblonga (mais ou menos nosso tronco cerebral) e o corpo caloso, o corpo estriado recebe as impressões que sobem para o cérebro e constitui a via pela qual os espíritos animais descem para as extremidades (Willis, 1978).

Os dois modelos se confrontam ao longo do século XVII. No que se referem à sede unitária da alma, os dados principalmente anatomoclínicos, vem no apoio de várias localizações: o corpo caloso, o centro oval, as paredes dos ventrículos. Mas a diversidade das teorias e o caráter pouco sólido das provas justificam a opinião de Albert de Haller (1708-1777) em uma carta à Charles Bonnet datada de 22 de janeiro de 1771: colocando a sede da alma globalmente na massa branca do encéfalo, estima-se que se em razão do caráter indivisível da alma, "a Filosofia 
favorece uma parte única, é indubitável que a anatomia não diz nada sobre esse assunto" (Bonnet, 1766, p. 90).

Nos dois casos, o cérebro prevalece como órgão do eu. $\mathrm{O}$ materialismo não necessita disso. De fato não é entre os materialistas das Luzes que encontramos as expressões mais completas sobre o sujeito cerebral nascente. Por exemplo, Julien Offray de La Mettrie (1709-1751) explica que se a sede da alma tem uma certa extensão ou se a alma tem diferentes sedes no cérebro, então ela não é inextensa e não existe enquanto substância imaterial ( $\mathrm{La}$ Mettrie, 1987). Mas é acreditando na alma que ainda durante certo tempo elaboram-se as psicologias empíricas. Dois dos mais importantes pensadores psicológicos das Luzes, o escocês David Hartley (1705-1757) e o genebrino Charles Bonnet (1720-1793) são cristãos convictos. Ora, precisamente porque eles aderem à definição do ser humano como composto de alma e de corpo, procuram compreender $\mathrm{o}$ funcionamento mental enfatizando $\mathrm{o}$ papel do cérebro e dos nervos como sede da alma e como elo entre as duas substâncias (Bonnet, 1760, Hartley, 1967). Trata-se, porém, de neuropsicologias conjecturais e o cérebro permanece, largamente por razões técnicas, difícil para ser examinado cientificamente (Begley, Wright, Church, Hager, 1992, Brazier, 1988, Clarke, O’Malley, 1968, Finger, 1994). A cerebralização ou neurologização do psiquismo, levemente avançada nas psicologias das Luzes, não se origina, portanto dos conhecimentos sobre a função e a estrutura do cérebro, mas da corrente que os precede, em direção a uma antropologia da cerebralidade.

\section{Das origens do sujeito cerebral: o ser humano na tradição cristã}

Apesar da importância que atribuem ao cérebro, não são nem a fisiologia galênica, nem a psicologia do século XVIII que determinam a emergência do sujeito cerebral. A fim de compreender os fatores científicos e filosóficos que conduzem a ela, convém lembrar que o cristianismo repousa sobre o dogma da Encarnação. Houve certamente debates sobre a natureza do corpo de Cristo e sobre a relação exata entre suas duas naturezas, humana e divina. Entretanto, conforme a posição que se tornou oficial, o Cristo é, ao mesmo tempo, Deus e um homem dotado de um corpo humano. Eis porque é inexato dizer que conforme a 
tradição cristã, "ser humano significa ser um espírito encarnado [embodied mind]" (Porter, 1992, p. 212). O cristianismo postula que o homem é feito de corpo e alma, mas não admite que a pessoa possa existir de outro modo que não somente composto por essas duas substâncias. O homem não é simplesmente alguém que tem um corpo, mas alguém cuja existência é corporal (Bynum, 1995, Keenan, 1994, Vergote, 1979).

A conseqüência mais radical de tal antropologia concerne à ressurreição dos corpos. A história dos debates sobre esta doutrina ilustra admiravelmente a origem e as implicações do sujeito cerebral (Vidal, 2002). Ressuscitando, supõe-se que cada um de nós retome seu próprio corpo. Derivam daí problemas complexos, mesmo além da questão de saber como o corpo se reformará e será "o mesmo" apesar das novas propriedades que o tornam "espiritual". Cristo tendo declarado que "nenhum cabelo de sua cabeça será perdido" (Lucas 21. 18), os teólogos d'Origenes e Atenágoras a Santo Agostinho e São Tomás de Aquino perguntam-se onde terminará a substância do corpo terrestre. Para que corpo, por conseguinte, retornará a carne de indivíduo devorado por um canibal ou por um animal posteriormente comido pelos seres humanos? As respostas variam no decorrer dos séculos, mas todas insistem na identidade do corpo terrestre e do corpo espiritual como condição indispensável à identidade dos ressuscitados. Não se concebe uma pessoa sem o corpo inteiro, nem a identidade pessoal sem identidade corporal.

Esta antropologia é questionada no fim do século XVII. Observa-se então uma desencarnação relativa da noção de pessoa, uma psicologização da identidade pessoal e uma focalização crescente do corpo sobre o cérebro. De uma parte, conforme a filosofia corpuscular da matéria, essa é uniforme e formada por partículas cujos "acidentes" mecânicos (tais quais o movimento ou a posição no espaço) explicam todos os fenômenos naturais. $\mathrm{Na}$ medida em que as coisas não diferem pelos seus componentes materiais últimos, elas podem se transformar, em determinadas condições, em não importa qual outra coisa. Aplicada a ressurreição, uma tal filosofia implica que um corpo ressuscitado (e conseqüentemente uma pessoa) não necessita ser formada pela mesma matéria que o corpo terrestre 
correspondente para poder ser dito "o mesmo". A continuidade material perde-se enquanto elemento constitutivo da identidade pessoal.

\section{A pessoa e seu cérebro}

Por outro lado, em 1694, na segunda edição de seu 'Ensaio concernente ao entendimento humano' (Locke, 1951), John Locke (1632-1704) distingue o 'homem' da 'pessoa', e define a identidade dessa como uma continuidade da consciência e memória. Se a consciência de uma pessoa permanecesse fixa ao seu dedo mínimo enquanto esse é separado do resto do corpo, para Locke é "evidente que o dedo mínimo seria a mesma pessoa" ( $§$ 17); a alma de um príncipe no corpo de um sapateiro o tornaria a mesma pessoa que o príncipe, apesar de que o homem seria diferente ( $§ 15)$. A partir daí, a sentença do Juízo Final se justificará "pela convicção em si de onde estarão todos os Homens, que em qualquer Corpo que eles apareçam, ou a qualquer Substância que este sentimento interno esteja ligado, que eles tenham eles mesmos cometido tais ou quais ações, que eles merecem o castigo que lhes é infligido por tê-las cometido" (§ 27). Dentro de tal noção de 'eu' ou de 'pessoa' (sinônimos em Locke, § 26), não diremos mais que somos um corpo, mas que temos um corpo. Objetivado e distanciado do eu, o corpo revela-se ser, na perspectiva do "individualismo possessivo", uma coisa que possuímos e não mais o que somos (Taylor, 1989).

A identidade pessoal torna-se assim psicológica e independente da identidade corporal. Mas a desencarnação não é total. $\mathrm{Na}$ medida em que a pessoa depende da memória e da consciência, o cérebro é a única parte do corpo de que ela necessita para ser ela mesma. Bonnet, cujo retrato o mostra meditando sobre a vida futura [Figura 2], retira daí as conseqüências para a doutrina da ressurreição. Ele especula que nossos cérebros abrigam uma espécie de minúsculo "cérebro indestrutível" que, combinado a propriedades do tipo embriológico, se desenvolverá quando do Juízo Final, restituindo a cada um sua personalidade e lhe concedendo um corpo diferente do terrestre. O que interessa a partir daí, é a união da alma e do cérebro. Bonnet dá a esta primeira forma de sujeito cerebral uma expressão sucinta quando escreve que "se a Alma de um Huron pudesse herdar o cérebro de Montesquieu, Montesquieu ainda criaria [Bonnet $\mathrm{C}$. 1760, § 771]. 


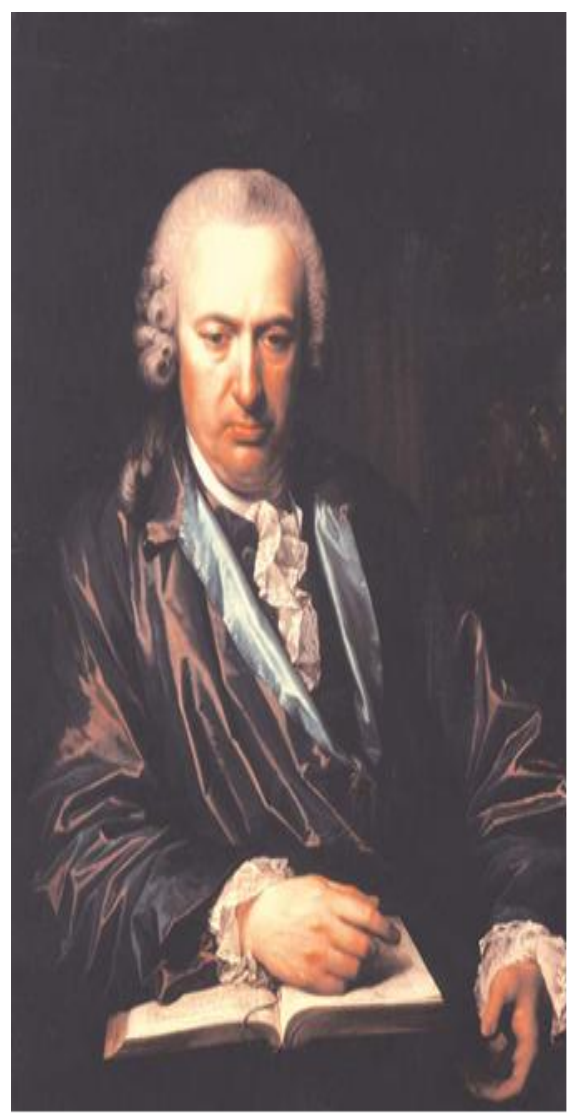

$\mathrm{Na}$ ausência cada vez maior do conceito de alma, esta visão de ser humano e do lugar do cérebro fortalecese consideravelmente no século XIX (Breidbach, 1997, Hagner, 1997). A frenologia é o exemplo mais conhecido (Renneville, 2000). Fundamentada nas teorias do médico vienense Franz Joseph Gall (1758-1828), ela é ao mesmo tempo uma psicologia das faculdades, uma teoria do cérebro, e um método para estudar o caráter e as aptidões. Repousa sobre várias suposições: o cérebro é o órgão da mente; a mente é composto de capacidades inatas; cada uma dessas
Figura 2. CHARLES BONNET (1720-1793) óleo sobre tela por Jens Juel, 1777, biblioteca pública e universitária, Genebra. Fotografia: Centro de Iconografia de Genebra

"M. Juel (escreve Bonnet), pintou-me enquanto eu estava mergulhado em uma profunda meditação sobre a reconstituição e o aperfeiçoamento futuros dos seres vivos. Percebemos, suficientemente, a dificuldade para transmitir esse caráter meditativo; mas para os grandes talentos, inspirados pela genialidade, nada é difícil". (C. Bonnet, obras, vol.1). O livro, uma Bíblia, está aberto na primeira epístola de São Paulo aos Coríntios, texto fundador da doutrina cristã da ressurreição. Nele distinguimos, no alto da página, "o que tu semeias não é vivificado, se primeiro não morrer."; no alto da outra página, "Onde está, ó morte, a tua vitória? Onde está, ó morte, o teu aguilhão?” (1 Cor.15.36 e 55)

capacidades tem sua própria sede ou "órgão" dentro do cérebro; o tamanho de um órgão é proporcional a força da capacidade que lhe corresponde; o cérebro é moldado pelo tamanho desses órgãos; o crânio devendo sua forma ao cérebro, as proeminências de sua superfície revelam as aptidões e as inclinações individuais.

As proposições desses órgãos, numerosas e variadas como mostra a Figura 3, revelam-se como imaginárias. Contudo, algumas premissas frenológicas parecem confirmadas na segunda metade do século XIX, quando acontecem grandes progressos no 
conhecimento

do

cérebro,

mentais supõem que as qualidades

principalmente a respeito das

positivas ou negativas dos sujeitos estão

localizações e da citoarquitetura. As

inscritas nos seus cérebros. Desde

descobertas neurocientíficas confirmam

então, o postulado neurofilosófico de

a idéia de que o cérebro é o órgão do eu.

uma correlação entre os estados

Esta crença se concretiza em inúmeros

domínios, desde a anatomopatologia e a

localização das doenças psíquicas até a

antropologia física e a diferenciação de

raças e de sexos. As pesquisas sobre os

cerebrais e psicológicos não perdeu em

nada a sua força; pelo contrário, foi

reforçado graças as imagens produzidas

pelas técnicas digitais de imagem

cerebral.

gênios, os criminosos e os doentes

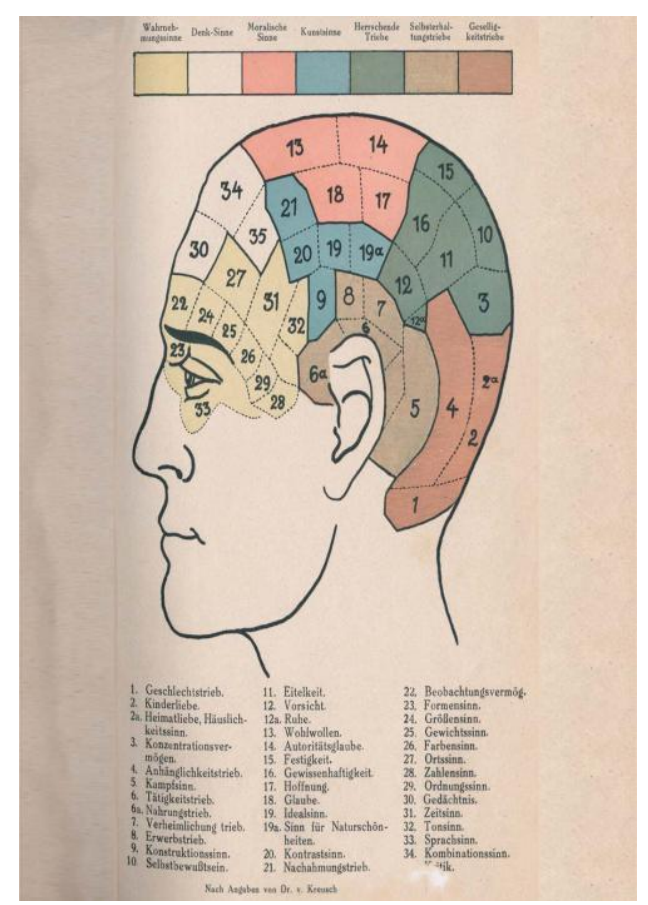

Figure 3. Versão tardia de uma cabeça frenológica. Em amarelo os sentidos da percepção (da faculdade de observação à linguagem); em branco aqueles do pensamento (memória, sentido de combinação crítica); em rosa, os sentidos morais (benevolência, crença na autoridade, esperança, crença); em azul, os sentidos artísticos (construção, imitação, contraste, ideal e sentido da beleza natural); em verde, os instintos dominantes (poder de concentração, segurança, vaidade, prudência, calma, firmeza, meticulosidade); em cinza, aqueles da conservação (luta, ação, nutrição, dissimulação, aquisição); em marrom, os instintos de sociabilidade (pulsão sexual, amor pelos filhos, amor pela pátria e pela família).

In Max von Kreusch, Praktische Phrenologie. Allgemeinverständlicher Leitfaden der CharakterBeurteilung auf Grund der Kopfform für Unterricht und Selbstausbildung [frenologia prática. Guia fácil para julgar os caracteres conforme a forma da cabeça, para o ensinamento e instrução própria], Berlin, Verlag Kreusch, 1921.

[Figura 4]. Essas imagens divulgadas pela mídia parecem imediatamente legíveis; e temos a tendência de ver nelas um verdadeiro retrato do que nós somos (Dumit, 2004). 


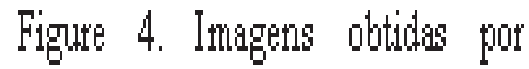
tothografia atrowes de etrissono de

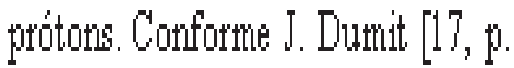

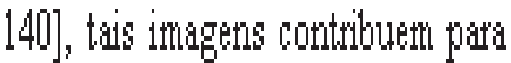

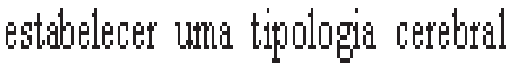
dos tidididos (Gos, coth tetardo mental, depressivo). Fonte: Beglet et al. [3]. p. 4 .

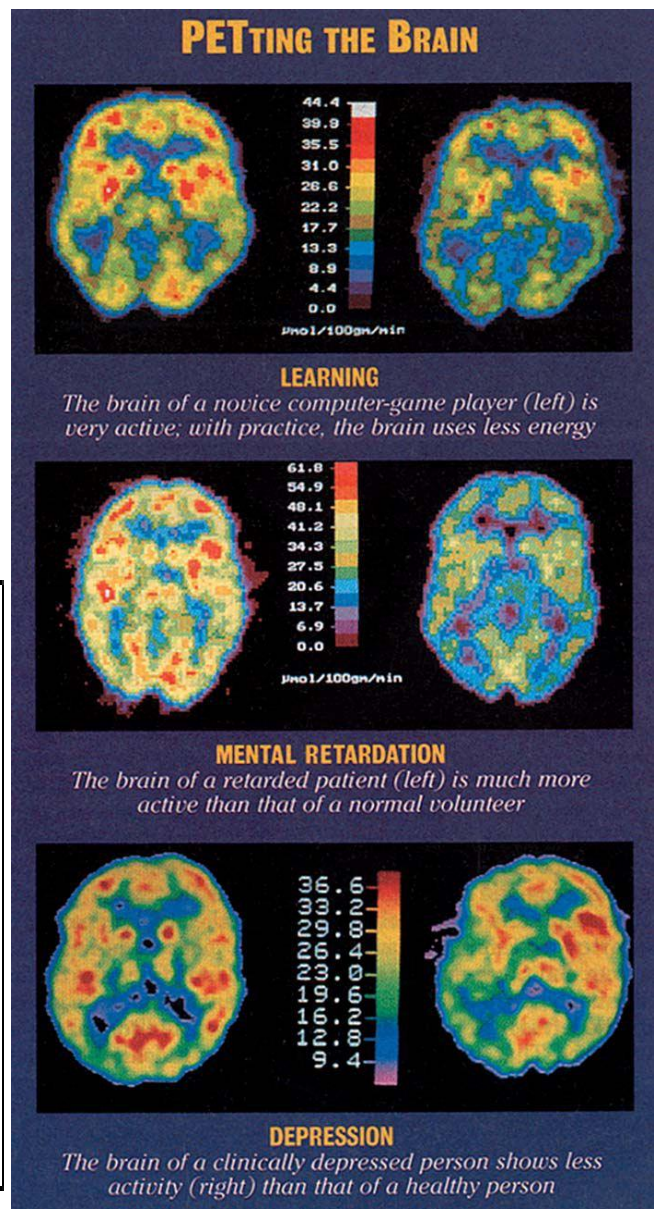

\section{O cérebro e a filosofia da identidade pessoal}

Os desenvolvimentos históricos esboçados acima contribuíram para estabelecer a antropologia da cerebralidade implícita nos desejos de imortalidade através da neuropreservação evocadas no início. Jonathon Keats e os adeptos da criogenia personificam o sujeito cerebral. Um momento crucial, a cristalização desse enquanto figura chave do pensamento contemporâneo, foi a utilização de ficções ao estilo de

John Locke, nas discussões filosóficas sobre a identidade pessoal. De acordo com meu conhecimento, o primeiro exemplo encontra-se no Self Knowledge and Self Identity, livro de Sidney Shoemaker, lançado em 1963.

$$
\text { Examinando os critérios }
$$
corporais e da identidade pessoal, Shoemaker apresenta a ficção lockeana da alma do príncipe no corpo do sapateiro descrevendo-a como um raciocínio concernente a uma mudança de corpo (change-of-body-argument), e 
como significando que uma pessoa pode cessar de ter o corpo que havia tido, o seu, no passado, obtendo um novo (Shoemaker, 1963, p. 22). Tentando aprofundar a questão, Shoemaker imagina que a medicina inventou uma técnica graças a qual um cérebro pode ser extraído do crânio de um paciente, para ser concertado. Ora um dia após a operação, assistentes invertem os cérebros de Brown e Robison. Um dos homens morre. O outro, que Shoemaker batiza Brownson, tem o corpo de Robison e o cérebro de Brown. Quando Brownson retoma a consciência, ele se espanta com sua aparência; seu corpo, ele diz, é o cadáver deitado no leito vizinho! Quando lhe é perguntado seu nome ele responde "Brown", reconhece a mulher de Brown, bem como sua família, e pode descrever os acontecimentos da vida de Brown. Em suma, ele tem todos os traços psicológicos que tinham sido de Brown.

Mesmo que Brownson tenha o corpo de Robison, pensamos que ele é na realidade Brown. Ele mudou de corpo, mas tem a mente, a biografia e a personalidade de Brown. Shoemaker não retira dessa experiência a conclusão de que a identidade do cérebro constitui o elemento definidor da identidade pessoal. Se apesar da troca de órgãos,
Brownson agisse da maneira de Robison, não diríamos que ele é Brown apenas porque tem o cérebro desse. $\mathrm{O}$ filósofo infere daí que a relação entre estado do cérebro e os traços psicológicos da pessoa é “causal e contingente", mas não "logicamente necessária”. O fato de que Brownson tenha o cérebro de Brown explica que ele tenha a psicologia de Brown - mas nada mais. Conseqüientemente, se decidirmos que Brownson é Brown, é porque privilegiamos $\mathrm{o}$ critério psicológico em detrimento da "não identidade corporal" (Shoemaker, 1963, p. 24-25). Evidentemente, falando de "mudança de corpo" e de "não identidade corporal", Shoemaker parece identificar o corpo ao corpo descerebrado, e esquecer que o cérebro é um órgão corporal. Entretanto, o que não era verdadeiro nos anos 60 tornouse depois, considerando que, quando se fala do cérebro na mídia, poucas imagens são tão divulgadas quanto a dicotomia entre o corpo e o cérebro. "O cérebro", pode-se ler no New Scientist, "não o corpo, faz com que os atletas se sintam fatigados" (J. Randerson, "Brain not body makes athletes feel tired", número de 29/07/04).

A utilização de ficções cirúrgicas do cérebro foi durante longo 
tempo um dos principais instrumentos para pensar filosoficamente a identidade pessoal. O cérebro impunha-se como limite somático do eu, de modo que eu cesso de ser eu mesmo se dele sou amputado. Confim da identidade, até órgão consubstancial do eu, o cérebro aparece como uma das fronteiras maiores da ciência e como o desafio principal de saber sobre o que faz o ser humano enquanto humano. Além de sua função de causa, fundamento material ou condição de possibilidade, ele possui certo primado ontológico. $\mathrm{X}$ com $\mathrm{O}$ cérebro de $\mathrm{Y}$ é $\mathrm{Y}$; não podemos trocar de cérebro sem nos tornarmos outro. $\mathrm{O}$ critério cerebral invalida o critério corporal de identidade apenas se imaginamos o corpo como se fosse um corpo descerebrado. Todavia, ele apóiase sobre uma redução radical do corpo próprio, sobre uma redefiniçãa do corpo como sendo "aquilo que, materialmente falando, é fundamentalmente a pessoa". Desde então, "uma pessoa P é idêntica a uma pessoa $\mathrm{P}^{*}$ se e somente se $\mathrm{P}$ e $\mathrm{P}^{*}$ são dotadas de um único e mesmo cérebro funcional" (Ferret, 1993, p. 30). Tal é a fórmula lógica do sujeito cerebral. Ter o mesmo cérebro é ter o mesmo corpo - e ser a mesma pessoa.

Não há necessidade de aderir a tais fórmulas para agir em função de uma representação do homem como sujeito cerebral. Essa representação, problemática mesmo na aplicação corrente dos critérios da morte cerebral (Schlich, Wiesemann, 2001), manifestase, como percebemos, em numerosos campos de atividade. Além da neurofilosofia, da psicologia e das neurociências, além também das neurodisciplinas nascentes, ela inspira toda uma galáxia em expansão de neurocrenças e de neuropráticas concernente ao bem estar e ao "desenvolvimento pessoal", ao esoterismo, até mesmo a escatologia. As técnicas de imagem cerebral engendram uma imagem digital da categoria de pessoa que modifica os indivíduos condicionando-os a percepção que tem de si mesmos (Dumit, 2004). E mesmo que as práticas de modificação corporal pareçam designar o corpo como sede de identidade pessoal, elas implicam uma relação com o corpo tal qual o consideramos como uma coisa que nós possuímos, antes do que como algo que nós somos (Andrieu, 2002, Featherstone, 2000, Le Breton, 2002).

\section{Ser de carne}

Vimos que a noção de ser humano como sujeito cerebral constitui 
uma ruptura com a tradição cristã e supõe uma psicologização, bem como uma relativa desencarnação dos critérios definidores da identidade pessoal. Se tal visão de homem não é evidentemente a única na cultura contemporânea, ela é sem contestação uma das principais. Convém, portanto encará-la e interrogála sobre seu alcance, seus limites, suas conseqüências. A redução da identidade à cerebralidade e do corpo próprio ao cérebro, a relegação da experiência vivida, da história do sujeito, do contexto social ou de seus modos de ser no mundo, comportam seguramente perigos quando, no momento de tomar decisões políticas, jurídicas ou médicas, trata-se de pensar no que é o homem - e de conseqüentemente agir. É necessário destacar que a crítica do sujeito cerebral não exige que se negue o papel fundamental do cérebro. Kathleen Wilkes, por exemplo, no seu brilhante Real People. Personal identity without thought experiments, põe em questão o valor das ficções filosóficas (Wilkes, 1988). Isso não a impede de consagrar numerosas páginas ao cérebro, insistindo na necessidade de não simplificar exageradamente a informação científica e de não limitar o cérebro ao córtex. Dentro de outro estilo, Francisco Varela partia de uma crítica da equação cérebro-corpo e do neuroreducionismo eliminativo para propor uma neurofenomenologia cujo propósito é de reintegrar nas neurociências a corporeidade e a experiência pessoal (Varela, 1996, Varela, Thompson, Rosch, 1991). Quanto a Paul Ricoeur ele opõe o sujeito cerebral (que ele não identifica como tal) ao "si (soi) como carne" e a "relação vivida" (então fenomenologicamente crucial) que podemos estabelecer com as partes do corpo ligadas ao movimento (a mão), a percepção (o olho), a emoção (o coração), ou a expressão (a voz) (Ricoeur, 1990).

Essas tomadas de posição fazem por si só parte de um universo marcado pela figura do sujeito cerebral. A tarefa de examinar este universo com profundidade permanece a ser feita. Ela não é de modo algum simples, visto que não podemos ser sem ao menos uma parte do cérebro, e que estamos mergulhados em uma cultura da cerebralidade que nos molda. Os neurotransmissores nos fazem sentir, mas no cérebro, em si, nenhuma sensação é sentida. Quem praticam neurofitness querem que seu cérebro "se sinta mais jovem"; contudo não é neste órgão que eles podem localizar uma 
cinestesia qualquer. Entretanto, dada a natureza da psicologia - e do cérebro humana, é possível que as neuropráticas e os neurodiscursos em voga acabem por dar ao cérebro "o status fenomenológico" que segundo Ricoeur lhe falta. Trata-se aí de questões abertas, como são ainda a maioria daquelas que dizem respeito ao sujeito cerebral. Aqui eu quis somente dar os primeiros passos e esboçar uma problemática, mas eu não poderia terminar sem dizer minhas preferências, pelo menos indiretamente, oferecendo um símbolo que as resumem.

Em 1991, Helen Chadwick cria uma obra de arte desconcertante (Figura 5). Trata-se de uma fotografia impressa em uma placa de vidro e iluminada por trás. Seu título: 'Auto-retrato'. Substituindo o rosto por um cérebro, Chadwick parece dizer que ela é esse órgão. Entretanto, o cérebro reproduzido não pode ser o seu; o são em contrapartida as mãos, elemento tradicional do auto-retrato. Elas seguram o cérebro de modo a evocar um gesto de oferenda ou de devoção, sacralizando assim o órgão e sublinhando sua fragilidade. Com sua forma única e reconhecível com as marcas e adornos que lhes são próprios, as mãos seguram o cérebro sobre $o$ fundo de um tecido cor de carne, cujas dobras evocam ao mesmo tempo as circunvoluções e a gola de renda que destaca o rosto em tantos grandes retratos barrocos. $\mathrm{O}$ conjunto remete a cerebralidade, mas também ao corpo inteiro da artista, a seu trabalho, a sua individualidade, a sua história, a seu meio. Finalmente, não é "Eu sou meu cérebro" que diz o auto-retrato de Helen Chadwick. Antes se o cérebro é visto no centro da obra de arte, ele atesta que a pessoa que criou a obra não é redutível a seu cérebro. 


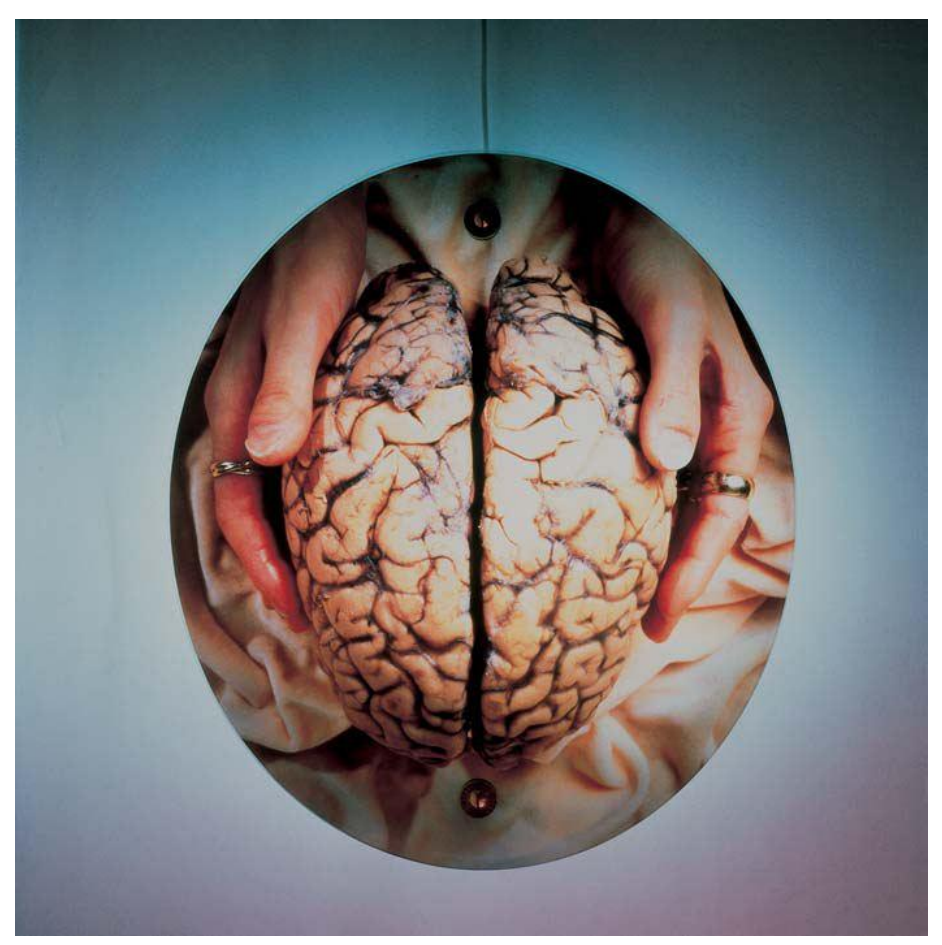

Figure 5. HELEN

CHADWICK, Autoretrato (1991)

(C) Helen Chadwick Estate.

Com autorização, Zelda Cheatle Gallery (Londres)

\section{Referências}

Alcor Life Extension Foundation. http://www.alcor.org/FAQs/faq02. html\#neuropreservation.

Andrieu B. (2002). La nouvelle philosophie $d u$ corps. Ramonville: Éditions Érès.

Aristóteles. (1966). De l'âme [De anima]. Ed. A. Jannone, trad. E. Barbotin. Paris: Les Belles Lettres.

Baertschi B. (1992). Les rapports de l'âme et $d u$ corps. Descartes, Diderot et Maine de Biran. Paris: Vrin.

Begley S., Wright L., Church V. \& Hager M. (1992). Mapping the Brain. Newsweek 20 avril: 40-44.
Blank R.H. (1999). Brain Policy: How the New Neuroscience Will Change Our Lives and Our Politics. Washington, D.C.: Georgetown University Press.

Bonnet C. (1760). Essai analytique sur les facultés de l'âme. Oeuvres d'histoire naturelle et de philosophie. Neuchâtel: Samuel Fauche, 1779-1783, tomo 6 (vol. 8).

Bonnet C. (1766). "Réflexions sur le siège de l'Ame". Dans “Essai d'application des principes psychologiques de l'auteur [...]", Oeuvres d'histoire naturelle et de philosophie. Neuchâtel: Samuel Fauche, 1779-1783, tome 7 (vol. 9). 
Brazier M. A. B. (1988). A History of Neurophysiology in the Nineteenth Century. New York: Raven Press.

Breidbach O. (1997). Die Materialisierung des Ichs. Zur Geschichte der Hirnforschung im 19. und 20. Jahrhundert. Frankfurt: Suhrkamp.

Bynum C.W. (1995). Why all the Fuss About the Body? A Medievalist's Perspective. Critical Inquiry 22: $1-33$.

Changeux J.-P. (2000). La révolution des neurosciences. Label France, $\mathrm{n}^{\circ}$ 38. http://www.france.diplomatie.fr/la bel_france/FRANCE/DOSSIER/2 000/09neuro.html.

Clarke E. \& Dewhurst K. (1972). An illustrated history of brain function. Oxford: Sandford.

Clarke E. \& O'Malley C.D. (1968). The Human Brain and Spinal Cord. Berkeley: University of California Press.

Dahl R. William and Mary. (1979). Tales of the Unexpected. Harmondsworth: Penguin Books (Original 1960).

Descartes R. (1649). Les passions de l'âme. Oeuvres, ed. C. Adam et P.
Tannery (1897-1913). Paris: Vrin, 1982-1991, vol. 11.

Descartes R. (1664). Traité de l'homme. Dans Oeuvres, ed. C. Adam et P. Tannery (1897-1913). Paris : Vrin, 1982-1991, vol. 11.

Dumit J. (2004). Picturing Personhood. Brain Scans and Biomedical Identity. Princeton: Princeton University Press.

Featherstone M. (ed). (2000). Body Modification. London: Sage.

Ferret S. (1993). Le philosophe et son scalpel. Le problème de l'identité personnelle. Paris: Minuit.

Finger S. (1994). Origins of Neuroscience. A History of Explorations into Brain Function. New York: Oxford University Press.

Galien. (1995). L'âme et ses passions. Trad. V. Barras, T. Birchler et A.F. Morand. Paris : Belles Lettres. Hagner M. (1997). Homo Cerebralis. Der Wandel vom Seelenorgan zum Gehirn. Berlin: Berlin Verlag.

Harvey R. (1975). The Inward Wits. Psychological Theory in the Middle Ages and the Renaissance. Londres: Warburg Institute.

Hartley D. (1967). Observations on Man, his Frame, his Duty, and his 
Expectations. Hildesheim: G. Olms, (Original 1749).

Huarte J. (1989). Examen de ingenios para las ciencias. Madrid: Catedra, 1989 (Original 1575).

Investment Opportunity.

http://cnewmark.com/keats.html

Kemp S. (1990). Medieval Psychology. New York : Greenwood Press.

Keenan J.F. (1994). Christian Perspectives on the Human Body. Theological Studies 55 : 330-346.

La Mettrie J.O. de. (1987). Traité de l'âme. Oeuvres philosophiques. Paris: Fayard, vol. 1, (Original 1745).

Le Breton D. (2002). Signes d'identité. Tatouages, piercings et autres marques corporelles. Paris: Métailié.

Locke J. (1951). Ensaio sobre o entendimento humano. Coimbra: Univ. de Coimbra, (Original 1694).

Marcus S.J. (ed). Neuroethics. Mapping the Field. New York: Dana Press, 2004.

Porter R. History of the Body. (1992).

In P. Burke (ed) New Perspectives on Historical Writing. University Park, PA: Pennsylvania State University Press.

Renneville M. (2000). Le langage des crânes. Une histoire de la phrénologie. Paris: Les Empêcheurs de penser en rond.

Ricoeur P. (1990). Soi-même comme un autre. Paris: Seuil.

Schlich T., Wiesemann C. (eds). (2001). Hirntod. Zur Kulturgeschichte der Todesfeststellung. Frankfurt : Suhrkamp.

Shoemaker S. (1963). Self-Knowledge and Self-Identity. Ithaca: Cornell University Press, 1963.

Singel R. (2003). He Thinks, Therefore He Sells. http://www.wired.com/news/print/ 0,1294,60757,00.html.

Taylor C. (1989). Sources of the Self. The Making of the Modern Identity. Cambridge, MA: Harvard University Press.

Temkin O. (1973). Galenism. Rise and Decline of a Medical Philosophy. Ithaca: Cornell University Press. Varela F. (1996).

Neurophenomenology: A Methodological Remedy to the Hard Problem. Journal of Consciousness Studies 3: 330350.

Varela F., Thompson E., Rosch E. The Embodied Mind. Cognitive Science and Human Experience. (1991). Cambridge, MA: MIT Press. 
Vergote A. (1979). Le corps: pensée contemporaine et catégories bibliques. Revue théologique de Louvain 10: 159-175.

Vidal F. (2002). Brains, Bodies, Selves, and Science. Anthropologies of Identity and the Resurrection of the Body. Critical Inquiry 28: 930-974.

Vidal F. (2006). Les sciences de l'âme, XVIe-XVIIIe siècle. Paris: Champion.

Wilkes K.V. (1988). Real People. Personal Identity without Thought Experiments. Oxford: Clarendon Press.

Willis T. (1978). The Anatomy of the Brain. Trad. do latim, 1681. In W. Feindel (ed): The Anatomy of the Brain and Nerves. Birmingham: The Classics of Medicine Library, (Original 1664).

Wright J.P., Potter P. (eds). (1980). Psyche and Soma. Physicians and Metaphysicians on the MindBody Problem from Antiquity to Enlightenment. Oxford: Clarendon Press.

Fernando Vidal: Doutor em psicologia, diretor de pesquisa no Instituto Max Planck de História das Ciências (Berlim). Correspondência: Max Planck Institut für
Wissenschaftsgeschichte. Boltzmannstr. 22, D-14195 Berlin, Alemanha. E-mail: vidal@mpiwg-berlin.mpg.de

Tradução: Maria Elísia Flores Filósofa (UFRGS). Diplôme de Nancy Aliança Francesa de Porto Alegre. Email: melisiaflores@bol.com.br

Revisão técnica: Marcos Adegas de Azambuja - Doutorando em Psicologia Social - PUCRS (bolsista CNPq). E-mail:m_adegas@yahoo.com.br 